\title{
Quality is measured by more than the clinical outcome
}

I WAS AT A CONFERENCE RECENTLY AT WHICH A bereaved parent presented their experience of the loss of a child with congenital cardiac disease. Their description of their experience was moving and their distress and anger were evident as was their loss of trust in the clinical team that had looked after their child. We have made much progress in the management of children and young people with cardiac disease in recent years and the "success" of treatment has greatly improved. While we have much to be proud of, we seem to have taken a narrow view of how we measure the quality of care for cardiac disease in children. The focus is often on procedure related mortality, often hospital or thirty day mortality. For many conditions, the immediate mortality from surgery and other interventional procedures is now very low, and while this is an important and necessary measure of the quality of clinical care, it is no longer sufficient.

Increasingly researchers are reviewing longer term data $^{1,2}$ to try and determine the long term results of treatment. However, as I have commented before, such retrospective studies, subject to publication bias, are not a reliable measure of quality. ${ }^{3}$ They tell us what can be achieved, not what is being achieved. I have just finished updating a book chapter on tetralogy of Fallot with pulmonary atresia. There have been several studies published in the five years since the previous edition and impressive surgical outcomes have been reported for individual procedures, but despite this published evidence, I was unable to establish whether the overall success of treatment regimes for this difficult condition had improved. Success does not solely depend on the outcome of a single operation, since many patients have several operations and some are never suitable to achieve a definitive repair. If we are considering clinical outcomes as a measure of quality, then we must look at the overall outcome for all patients with the condition, not just those who are judged suitable for a specific operation or procedure. How else can we satisfactorily advise our patients and their families?
Selective publication of outcomes in successful series does not, of course, give us a measure of overall quality of care. One response to this has been the development of databases of outcomes of operations and interventions that include all patients. In the UK such a database was established as a result of a heavily publicised failure of a paediatric cardiac surgical service. The national database covering mortality for all cardiac operations and interventional procedures in children is now publicly available. ${ }^{4}$ Interestingly, one of the earliest observations from this database was that, for some conditions, mortality a year after surgery differed from the commonly quoted thirty-day mortality, highlighting the inadequacy of shortterm mortality measures. Databases, such as this, will give us, in time, what we need in terms of the long-term survival data for different cardiac conditions, free of publication bias. This will undoubtedly be of value, but mortality is only one measure of outcome.

We are increasingly seeing the publication of studies of other outcome measures. ${ }^{5-7}$ These studies consider quality of life, neurological and psychosocial measures in children with congenital heart disease. These alternative outcome measures are interesting and important, but are still not well developed or widely reported. Another important area of quality measurement is the level of satisfaction patients and their families have with the services. Children's and families' perception of the quality of care they receive, their views about the outcomes, so-called patient reported outcomes, is an area of study where still much work needs to be done.

There is one further aspect of clinical quality that is understood to be increasingly important in healthcare - patient safety. Modern healthcare is highly effective, but also carries a high degree of risk. What we are beginning to realise, somewhat belatedly, is that good clinical outcomes do not indicate that a clinical service is as safe as possible. That is why a well-respected clinical service, with 
good clinical outcomes, came to let down the parent that I referred to at the start of this article. Patient safety in treatment of congenital cardiac disease is the subject of occasional studies, ${ }^{8,9}$ but has not been studied to any great degree, and this is a deficiency that is in need of remedy.

Clinical quality therefore has several dimensions; firstly, clinical outcomes, beyond short-term mortality in specific groups. They should include long-term outcomes in wider populations with congenital cardiac disease and not just mortality, but outcomes related to quality of life, particularly outcomes built upon what patients and families tell us are important to them. Secondly, clinical quality has to be measured by the view of patients, even young children, and their families about the care they have received. Thirdly, a clinical service cannot be judged to be of good quality unless it can show it systematically assesses the risk of its care to patients and has put in place all the necessary actions to protect them from preventable harm. We would welcome submissions of well-researched studies of any of these aspects of clinical quality to Cardiology in the Young.

\author{
Edward Baker \\ Editor-in-Chief \\ E-mail: ctyeditor@cambridge.org
}

\section{References}

1. Canale LS, Monteiro AJ, Rangel I, et al. Mid-to-long term follow-up after surgical repair of atrioventricular septal defect with common atrioventricular junction and ventricular shunting with tetralogy of Fallot. Cardiol Young 2008; 18: 100-104.

2. Telagh R, Alexi-Meskishvili V, Hetzer R, Lange PE, Berger F, Abdul-Khaliq $\mathrm{H}$. Initial clinical manifestations and mid- and long-term results after surgical repair of double-chambered right ventricle in children and adults. Cardiol Young 2008; 18: 268-274.

3. Baker E. Trials and tribulations. Cardiol Young 2003; 13: 395-396.

4. http://www.ccad.org.uk/congenital

5. Tabbutt S, Nord AS, Jarvik GP, et al. Neurodevelopmental outcome after staged palliation for hypoplastic left heart syndrome. Pediatrics 2008; 121: 476-483.

6. Spijkerboer AW, Utens EM, Bogers AJ, Helbing WA, Verhulst FC. A historical comparison of long-term behavioral and emotional outcomes in children and adolescents after invasive treatment for congenital heart disease. J Pediatr Surg 2008; 43: 534-539.

7. Majnemer A, Limperopoulos C, Shevell M, Rohlicek C, Rosenbaltt B, Tchervenkov C. Developmental and functional outcomes at school entry in children with congenital heart defects. J Pediatr 2008; 153: 55-60.

8. Benavidez OJ, Gauvreau K, Del Nido P, Bacha E, Jenkins KJ. Comaplications and risk factors for mortality during heart surgery admissions. Ann Thorac Surg 2007; 84: 1-2.

9. Cohen MS, Jacobs JP, Quintessenza JA, et al. Mentorship, learning curves, and balance. Cardiol Young 2007; 17 Suppl 2: $164-174$. 